\section{Are We Ready to Share Data from Pharmacy Information Systems to Electronic Health Records?}

The use of electronic health records is emerging across North America, but adoption of this tool has been slow. ${ }^{1}$ A US survey conducted in 2008 revealed that $100 \%$ of pharmacy departments were computerized, but only $10 \%$ were using electronic health records. ${ }^{2}$ A Canadian survey conducted in 2009 revealed that only $6 \%$ of departments were using this type of medical record, ${ }^{3}$ even though the Canada Health Infoway is funding implementation plans for electronic health records in most Canadian provinces. ${ }^{4}$ Why is this process taking so long, given that pharmacy departments have been computerized for decades? Sharing clinical data for inpatients and outpatients through electronic health records will undoubtedly help to reduce the need to retranscribe information, as well as reducing errors, duplications, and omissions. It should also provide clinicians with an accurate overview of the state of patients' health, including clinical actions taken. Nevertheless, given the plethora of systems and processes that have already been implemented, data-sharing among existing systems constitutes a major challenge. In fact, these systems feature widely divergent data structures and processes for data management and record-keeping.

A limited normative framework exists to determine the optimal structure for data collected in pharmacy information systems and the way in which patients' medication orders are entered into electronic health records and other software. The American Society of Health-System Pharmacists has published a number of statements on robotization and information technologies, ${ }^{5,6}$ but neither the Canadian Society of Hospital Pharmacists nor any of the professional regulatory authorities in Canada have published professional guidelines for data maintenance or order exchange in health care settings.

We conducted a descriptive pilot project involving several hospital pharmacy departments in Montreal in June 2010. The objective was to describe the content of medication order labels appearing in medication administration records (MARs) produced by various pharmacy information systems and to consider the feasibility of sharing these data with electronic health records. For the pilot study, we prepared 10 prescriptions for a single theoretical patient. Thirteen (41\%) of 32 hospitals responded to our invitation to participate and returned a completed MAR for the theoretical patient.

For the most part, the MARs returned by the participating pharmacies included expected demographic and clinical data for the patient, except for creatinine clearance (included by only 10 of 13 pharmacies), body surface area (5 of 13), and intolerances (12 of 13). We observed a high disparity in terms of content of the MAR fields related to the medication orders. For instance, we identified up to 28 different fields or pieces of information for any given label (usually between 5 and 13), a variable number of lines per label (from 3 to 11), a variable number of characters per label (from 320 to 700), and a variety of fonts. Only one department was using TALLman lettering. The placement of the information on labels also varied (e.g., information related to the route of administration was sometimes repeated on the label), as did its content. For example, the trade name used usually did not refer to the brand dispensed, therapeutic class was mentioned in only some cases (6 of 13), and potential adverse effects were not always mentioned (although there were up to 18 different adverse effects for one of the drugs). Other points of variation were the syntax (e.g., "mg=ml" used by 8 of the 13 MARs, and " $\mathrm{ml}=\mathrm{mg}$ " used by 5) and units of measure for the same drug (e.g., "g" versus "mg"). Abbreviations were used by all 13 pharmacy departments.

Over the years, our expertise in pharmacy information systems has allowed us to observe that the structure of databases and the rules behind their creation and maintenance within these systems differ markedly among hospitals. Each system has its own design and its own variables, each with a truncated name, all performing differently in different situations. Although the meaning of a label on a MAR is usually (though not always) self-explanatory for nurses, physicians, and pharmacists, any information technology personnel involved in creating interfaces between pharmacy information systems and other software should be knowledgeable about the complexities underlying the information on the label.

Are we ready to share data from pharmacy information systems with inpatient and outpatient electronic health records? This pilot study indicates that the answer to this question may be "No". On the basis of our results, we suggest that pharmacists should seriously consider standardization of pharmacy information systems and MARs. Patient safety relies on information that is understandable, coherent, and predictable. Although pharmacists do adapt to individual requests from nurses or physicians to fulfill specific patient needs, the profession should consider standardizing data management policies, not only within individual hospital settings, but also within regions, provinces, and the country as a whole.

This pilot study suggests that the interface between different pharmacy information systems and also between these information systems and one or more electronic health records can be risky if such standardization does not happen and if data are exchanged without revealing the complete picture to all users. Medication order labels make sense when they can be read according their display, but interfacing the content elements behind the label can be risky, and messages can be difficult to interpret without a coherent and comprehensive display. 
The implementation of electronic health records is inevitable. ${ }^{7}$ As such, pharmacists should invest efforts in developing and adopting guidelines for data management and display in pharmacy information systems. In the meantime, to avoid slowing further development in the health care sector, safe datasharing from pharmacy information systems to inpatient or outpatient electronic health records could rely on electronic sharing of actual labels (e.g., in pdf format).

\section{References}

1. Study finds U.S. hospitals extremely slow to adopt electronic health records, citing cost [press release]. Boston (MA): Harvard School of Public Health; 2009 Mar 25 [cited 2010 Oct 23]. Available from: www.hsph.harvard.edu/news/press-releases/2009-releases/us-hospitalsextremely-slow-to-adopt-electronic-health-records.html

2. Pedersen CA, Schneider PJ, Scheckelhoff DJ. ASHP national survey of pharmacy practice in hospital settings: prescribing and transcribing2007. Am J Health Syst Pharm 2008;65(9):827-843.

3. Babich M, Bussières JF, Hall K, Harding J, Johnson N, Lefebvre P, et al., editors. Hospital pharmacy in Canada 2007/2008 report. Eli Lilly; 2008 [cited 2010 Oct 23]. Available from: www.lillyhospitalsurvey.ca/hpc2/ content/rep_2008_toc.asp

4. Canada Health Infoway [website]. Toronto (ON): Canada Health Infoway; [cited 2010 Sep 7]. Available from: www.infoway-inforoute.ca

5. Policy positions and guidelines (best practices): automation and IT. Bethesda (MD): American Society of Health-System Pharmacists; [cited 2010 Oct 30]. Available from: www.ashp.org/Import/
PRACTICEANDPOLICY/PolicyPositionsGuidelinesBestPractices/Brow sebyTopic/Automation.aspx

6. ASHP statement on the pharmacist's role in informatics. Bethesda (MD): American Society of Health-System Pharmacists; [approved 2006; cited 2010 Oct 30]. Available from: www.ashp.org/DocLibrary/ BestPractices/AutoITStInformatics.aspx

7. Khajouei R, Jaspers MW. The impact of CPOE medication systems' design aspects on usability, workflow and medication orders: a systematic review. Methods Inf Med 2010;49(1):3-19.

\section{Lionel Brisseau}

Research Assistant

Denis Lebel, BPharm, MSc, FCSHP

Assistant Director

Jean-François Bussières, BPharm, MSC, FCSHP

Director

Research Unit in Pharmacy Practice

CHU Sainte-Justine

Montréal, Quebec

Lionel Brisseau is also a pharmacy resident with the Universite de Nantes, Nantes, France. Denis Lebel and Jean-François Bussières are also affiliated with the Department of Pharmacy, CHU Sainte-Justine. Jean-François Bussières is a clinical professor in the Faculty of Pharmacy of the Université de Montréal.

\begin{tabular}{|c|c|c|}
\hline & Ad Page & Prescribing Information \\
\hline Eli Lilly / Insulin & 7 & - \\
\hline Hospira / Precedex & 4 & 61,62 \\
\hline Pharmaceutical Partners of Canada / Safety Ad & IFC & - \\
\hline Pharmaceutical Partners of Canada / Safety Ad & $\mathrm{OBC}$ & - \\
\hline Sandoz / Corporate & 2 & - \\
\hline
\end{tabular}

